\title{
ELECTROMYOGRAPHIC EVALUATION OF THE MASSETER AND TEMPORALIS MUSCLES ACTIVITY IN PATIENTS WITH COMPLETE DENTURE, IMPLANT SUPPORTED AND IMPLANT RETAINED MANDIBULAR OVERDENTURES. A CROSS-OVER STUDY
}

\author{
Shahinaz Sayed Mohamed Hassan *
}

\begin{abstract}
Purpose: This study was conducted to compare the electromyographic [EMG] activity of both masseter and the anterior temporalis muscles in patients with: Conventional complete dentures, Implant supported overdentures without attachments and, Implant retained overdentures with locator attachments.
\end{abstract}

Material and methods: Six completely edentulous male patients with atrophied mandibular ridges received upper and lower conventional complete denture. EMG activity were measured for both masseter and the anterior temporalis muscles during clenching without food, clenching hard (carrot) and soft (banana) foods. Measurements were made at time of denture insertion, one month and two months after. Two implants were installed in canine regions of the mandible. After osteointegration, healing abutments were connected and the mandibular denture were relined with hard acrylic resin. Measurements were repeated, then healing abutments were replaced with locator attachments, and measurements were repeated again.

Results: The highest EMG activity/amplitude of masseter and temporalis muscles, were noted with locator overdentures, and the lowest values were observed with conventional dentures. There was no statistically difference in muscle activity between implant supported overdentures and complete dentures. For all groups, muscle activity for masseter and temporalis muscles increased with advance of time. For both groups, muscle activity was significantly higher during clenching of hard food than clenching without food or with soft food

Conclusion: Within the scope of this study, implant retained overdentures are recommended for edentulous patients rather than conventional complete dentures or implant supported overdentures as it improves EMG activity/amplitude of masseter and temporalis muscles.

KEY WORDS: Complete denture, dental implant, overdentures, attachments, EMG activity.

\footnotetext{
* Lecturer, Department of Removable Prosthodontics, Faculty of Dentistry, Beni-suef University, Egypt.
} 


\section{INTRODUCTION}

Atrophic mandibular ridge represents many problems for patients seeking a complete denture due to insufficient area for distribution of masticatory force, pain during mastication, mucosal inflammation, poor retention and instability of the denture, difficulty in speech, and poor patient toleration. All these problems can cause dissatisfaction of the patient and poor quality of life ${ }^{1}$. Bone resorption that occurs in case of conventional complete dentures can render the current prosthesis inadequate in terms of both function and esthetics and can lead to the necessity of fabricating a new denture. Over time occlusion, esthetics and function may be compromised ${ }^{2}$. Implant insertion for edentulous patients have reported to contribute to the preservation of residual ridges, improvement of the masticatory parameters and patient satisfaction ${ }^{3}$. The use of implant supported over denture has excellent outcomes for the edentulous patients compared with the conventional dentures, due to reduced residual ridge resorption and improved retention and support of the prostheses ${ }^{4}$ resulting in better quality of life function ${ }^{5}$, chewing and masticatory functions ${ }^{6}$, nutritional status and general health ${ }^{7,8}$.

Mandibular implant overdenture treatment showed improved support, retention and stability as compared with conventional mandibular complete denture $^{9}$. This creates a more stable occlusion which provides better distribution of occlusal forces and a significant decrease in soreness and stomatitis in the anterior mandibular tissues in comparison with conventional dentures ${ }^{10}$. Compared to conventional dentures, the implant retained overdentures improve masticatory ability and patient perception of functions related to mastication ${ }^{11}$ especially for patients with resorbed mandibles ${ }^{12}$. In addition, these overdentures enhance maximum bite force ${ }^{13}$ and increase patient satisfaction and comfort during mastication.
Several attachments can be used to connect overdentures to the implants such as ball, bar, Locator, and resilient telescopic attachments ${ }^{14}$. Atrophied ridge requires stabilization, especially to horizontal forces ${ }^{15}$. The widely used Locator system has been advocated as an alternative single attachment to the established ball anchor ${ }^{16}$. Locators are low-profile resilient studs that can also provide a limited hinge movement and compensate for implant angulation up to 40 degrees $^{17}$. Moreover, it was estimated that the time required to fabricate a mandibular overdenture retained by implant with locator attachments was not significantly different than the time needed for the conventional denture treatment ${ }^{18}$

Electromyography of the masticatory muscles has been used to investigate the masticatory muscle behavior during function of the stomatognathic system during normal or abnormal conditions as occlusion and bruxism to evaluate the effectiveness of muscle activity with treatment ${ }^{19}$. The objective evaluation of masticatory function includes measurement related to the activity of masticatory muscles, the maximum biting force, the mastication time, and the particle size of different test foods ${ }^{20}$. The electrical output of a muscle, measured by electromyography (EMG), is proportional to the energy consumed to produce contractions ${ }^{21}$. Several investigations proved that the masticatory muscles activity increased when chewing hard food when compared to soft food ${ }^{22}$. The evaluation of the effect overdentures supported only by implants without attachment on EMG activity of masticatory muscles was not sufficiently investigated. Accordingly, the aim of the present study was to evaluate, within patient, the electromyographic activity of the masseter and temporalis muscles in patients wearing conventional dentures, implant supported overdentures without attachments and implant retained mandibular overdentures with Locator attachments. 


\section{MATERIAL AND METHODS}

\section{Patient selection}

Six completely edentulous patients ( 3 males and 3 females, age ranged from 55 to 60 years) with atrophied mandibular ridges were selected. The patients were selected according to the following criteria: 1) Patients free from any systemic disease that may interfere with dental implant placement and/or Osseo integration e.g. uncontrolled diabetes, hypertension, blood diseases and bone diseases. 2) Last extraction was at least 6 months before, 3) No T.M.J. disorders. 4) Patients were with angles class I. 5) Patients had healthy mucosa and adequate boneheight in the anterior mandibular region. Patients who had bone metabolic disorders, and diseases that may complicate surgical procedure as liver, heart, autoimmune diseases, radiation to head and neck and diabetes mellitus were excluded. Also, Heavy smokers (>10 cigarette per day) were excluded. All Patients were instructed about the treatment protocol and objectives prior to obtain an informed consent. The study was conducted according to the ethical principles of Helsinki declaration (http:/www.wma. net/) and approved by the faculty of dentistry, BeniSuef University ethical committee. (Approval no: \# FDBSUREC/09112020/SS).

\section{Surgical and prosthetic procedures}

All patients received new conventional upper and lower complete dentures constructed by bilateral occlusal balanced technique. The muscular activity (of the anterior temporalis and the superficial masseter muscles) was evaluated at time of denture insertion, one month and two months later after denture insertion. Each patient underwent a cone beam computerized tomography scan and lower denture was duplicated for making surgical stent. 24 hours before surgery, patients were premedicated by antibiotics (amoxicillin 628mg + clavulanic acid $125 \mathrm{mg}$, augmenting $\left.{ }^{\circledR} 1 \mathrm{gm}\right)$, and continued for five days after surgery. Two submerged root form endosteal implants 3.6 in width and $12 \mathrm{~mm}$ in height (Dentium, super line, South Korea) were inserted in the right and left mandibular canine regions following 2 stage surgical protocol using surgical stent. The implants were positioned in the osteotomy sites using the implant driver and were threaded into its final positions using a ratch with at least $35 \mathrm{Ncm}$ torque. The titanium cover screw was screwed into the occlusal opening of the implant and tightened with the hex screw driver. The mucoperiosteal flaps were then repositioned and sutured by interrupted sutures using black silk number 0000 . The patients were instructed to take their post-operative medications as previously prescribed. Patients were also instructed to use cold fomentation on the anterior region of the mandible for the first twenty-four hours, eat soft diet and avoid finger or tongue pressure at the implant sites. The mandibular dentures were relined with soft liner during the healing periods. One week later, sutures were removed. Patients were recalled after 3 months to allow osseointegrations. Fixture were uncovered with the aid of the surgical stent. A very small crestal incision was made over the implant exposing the covering screw. Then the cover screws were unthreaded, and 2 dome shaped healing abutments of suitable gingival height were selected according to thickness of mucosa to be extended above the mucosal surface about $2 \mathrm{~mm}$ (fig1). The soft liner was removed from the fitting surface of mandibular denture, the lower dentures were relived for making closed mouth relining impression technique while patients closed in centric occlusion with upper and lower dentures using medium body rubber base. After setting of the impressions, the dentures were sent to lab for relining of lower dentures with hard acrylic resin. The newly relined mandibular dentures were adjusted to fit the healing abutments and be sure that the healing abutments made contact with the fitting surface of mandibular overdentures with its top part only by using disclosing materials to avoid implant overloading. EMG activity (of the anterior temporalis and the superficial masseter muscles) were evaluated again at time of denture insertion, one month and two months later after denture insertion. After EMG measurements, the healing abutments were unthreaded and replaced 
by locator abutments (Dentium Co., Ltd, EMERGO EUROPE). The locator abutments were threaded to the implants (Fig 2). Blocking rings were placed over the abutments to relieve acrylic resin around the abutments and prevent excess acrylic resin to enter in peri-implant sulcus. Metal housing with processing inserts were snapped on the locator abutments (Fig 2). Using disclosing media, sufficient relieve was provided in the mandibular dentures over locator abutments to provide a space for Locators metal housing. Lingual vents were drilled in the lingual flange of the denture to allow escapement of excess acrylic resin material during the pickup procedure. The metal housings were picked to the tissue surface of the mandibular denture using auto polymerized acrylic resin while the participants close in retruded contact position. After polymerization of the acrylic resin, the mandibular denture was removed, excess acrylic resin around the abutments was removed to avoid unnecessary loading of the implants and the denture was finished and polished. Black processing inserts were removed using locator tool and replaced with blue nylon insert (extra light retention) (Fig 2) and dentures delivered to the participants and occlusion was refined. Patients were instructed to maintain strict oral and denture hygiene measures clinical evaluation was carried out to inspect the condition of the denture bearing structures, the implant abutments, the oral hygiene and the dentures. Electromyographic evaluation of both masseter and the anterior temporalis muscles was then repeated for all patients at denture insertion, one month and two months later after denture insertions.

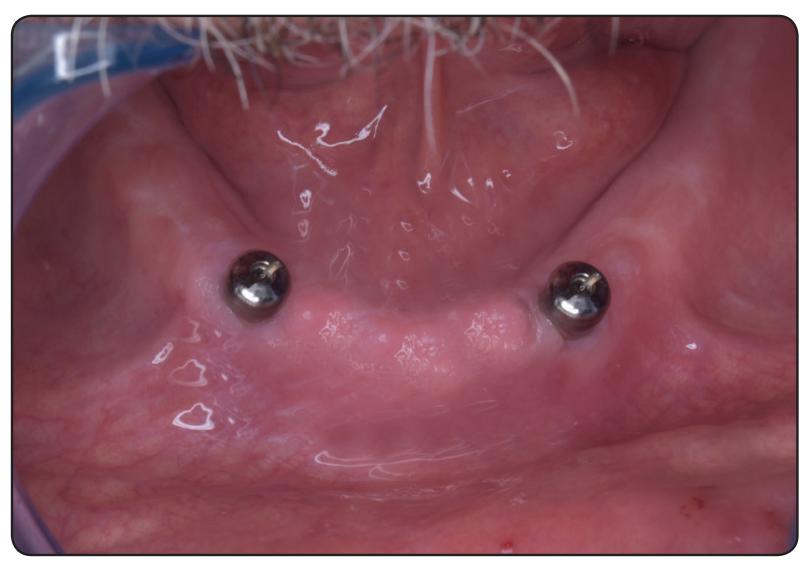

Fig. (1) Connection of healing abutments for implant supported overdentures

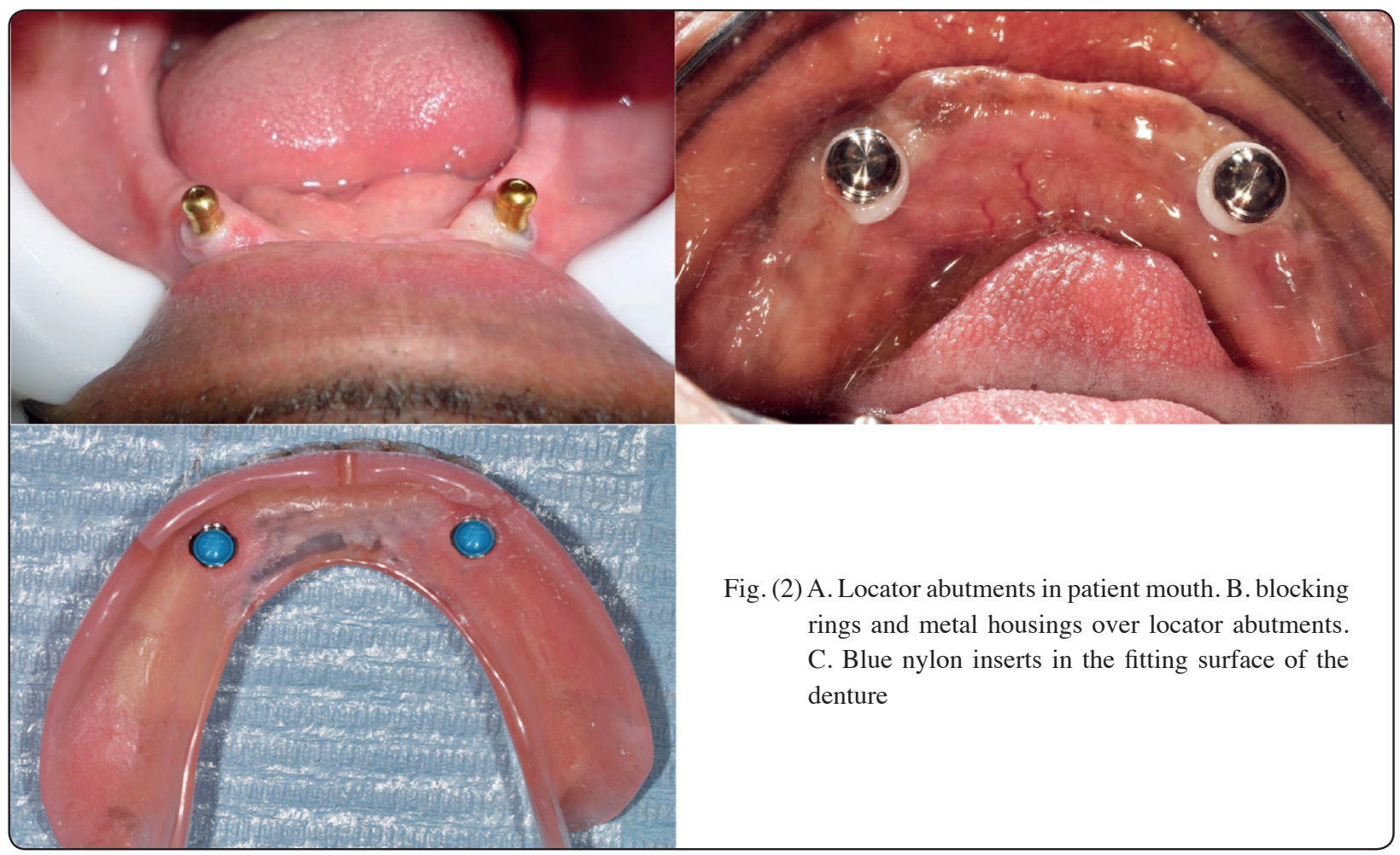




\section{Evaluation of EMG Activity of Masseter and an- terior temporalis muscles:}

The muscular activity (of the anterior temporalis and the superficial masseter muscles) was evaluated at time of denture insertion, one month and two months' later after wearing each prosthesis (conventional dentures, implant supported overdentures, and Locator overdentures). The patients were seated in an upright position. The skin over the muscles was cleaned with alcohol. Surface electrodes were placed on the bellies of the masseter muscle of the preferred chewing side of the patient ${ }^{6}$. The active electrodes were positioned on mid-longitudinal fibers of the muscle parallel, and the reference electrode was placed on the patient's forehead. For temporalis muscle while the patient clenching the position of the surface electrodes were determined through an imaginary horizontal line drawn from the outer canthus of the eye to the upper margin of the external auditory meatus. The electrodes were placed about $3 \mathrm{~cm}$ vertically upward from the midpoint of the horizontal line.

The electrodes were connected to the measuring system (MEB-9400K, NIHON KOHDEN). Electro conductive gel (Elefix, NIHON KOHDEN) was used on the electrode before fixing it to the skin using adhesive bandage tape. Each patient was instructed to clench on teeth without food and to clench on a sample (dimensions $3 \times 1 \times 1 \mathrm{~cm}$ ) of hard (carrot) and soft (banana) foods ${ }^{6}$ until the foods became ready for swallowing. Analysis of EMG signals was performed with programs of EMG equipment. EMG signals were amplified and filtered (20 $\mathrm{Hz}$ to $10 \mathrm{KHz}$ ), full wave rectified, and smoothed electronically ${ }^{6}$. Four peaks of EMG muscle activity were evaluated and averaged. The operator repeated the test five times (separated by a rest period of at least 2 minutes) for each type of food, and the mean was subjected to statistical analysis.

\section{Statistical analysis:}

Data were collected, tabulated, and analyzed statistically, and illustrated in tables and figures. The data were summarized as mean and standard deviation values for the EMG results. The data collected were analyzed using IBM SPSS Statistics version 22.0 software (IBM Corp., Armonk, NY, USA). Mean values were compared by one-way ANOVA for comparisons between the three denture types (conventional dentures, implant supported overdentures, and Locator overdentures) and by repeated measures ANOVA for comparisons of the effect of time (at time of denture insertion, one month and two months' later) and clenching conditions (without food, with hard food and with soft food) in each group. The level of significance was set at $5 \%$ for all statistical analyses.

\section{RESULTS}

All patients completed the analysis without dropouts as the follow up period was small and all patients attend the follow up recalls. The implant survival rate was $100 \%$. Comparison of the three groups regarding Masseter muscle activity at different follow up periods and different clenching conditions is presented in table 1. Comparison of three groups regarding Temporalis muscle activity at different follow up periods and different clenching condition is presented in table 2 . There was a significant difference in Masseter and temporalis muscle activity between groups (conventional dentures, implant supported overdentures, and implant retained overdentures) at all clenching conditions at time of denture insertion $(p=.001)$, one month $(p=.002$ for masseter, .004 for temporalis) and two months' ( $\mathrm{p}=.001)$ later. At all observation times, implant retained overdentures showed significant higher Masseter and temporalis muscle activity than conventional denture or implant supported overdentures. No significant difference in Masseter and temporalis muscle activity between conventional denture or implant supported overdentures 
TABLE (1) Comparison of three groups regarding Masseter muscle activity at different follow up periods and different clenching conditions

\begin{tabular}{|c|c|c|c|c|c|c|c|c|}
\hline & & \multicolumn{2}{|c|}{ At delivery } & \multicolumn{2}{|c|}{ One month } & \multicolumn{2}{|c|}{2 months } & \multirow{2}{*}{ P value } \\
\hline & & Mean & SD & Mean & SD & Mean & SD & \\
\hline \multirow{3}{*}{ Complete denture } & Max. cln & 45.57 & 19.65 & 65.54 & 18.68 & 80.54 & 14.58 & $0.0001 *$ \\
\hline & Hard food & 80.32 & 10.22 & 100.45 & 16.24 & 122.32 & 12.24 & $0.001 *$ \\
\hline & Soft food & 60.64 & 10.38 & 80.28 & 13.33 & 99.54 & 14.31 & $0.001 *$ \\
\hline \multirow{3}{*}{$\begin{array}{c}\text { Implant supported } \\
\text { overdenture }\end{array}$} & Max. cln & 50.55 & 12.29 & 70.47 & 19.27 & 85.58 & 15.27 & $0.001 *$ \\
\hline & Hard food & 105.48 & 18.14 & 120.46 & 10.14 & 130.78 & 13.24 & $0.001 *$ \\
\hline & Soft food & 70.73 & 17.57 & 85.78 & 18.55 & 105.78 & 16.65 & $0.001 *$ \\
\hline \multirow{3}{*}{$\begin{array}{l}\text { Implant retained } \\
\text { overdenture }\end{array}$} & Max. $c \ln$ & 65.15 & 13.15 & 80.18 & 16.17 & 100.15 & 18.17 & $0.03 *$ \\
\hline & Hard food & 112.25 & 15.42 & 130.75 & 14.44 & 150.55 & 15.54 & $0.02 *$ \\
\hline & Soft food & 90.15 & 16.71 & 100.45 & 17.75 & 120.35 & 18.65 & $0.02 *$ \\
\hline P value & & \multicolumn{2}{|c|}{$0.001 *$} & \multicolumn{2}{|c|}{$0.002 *$} & \multicolumn{2}{|c|}{$0.001 *$} & \\
\hline
\end{tabular}

*p is significant at $5 \%$

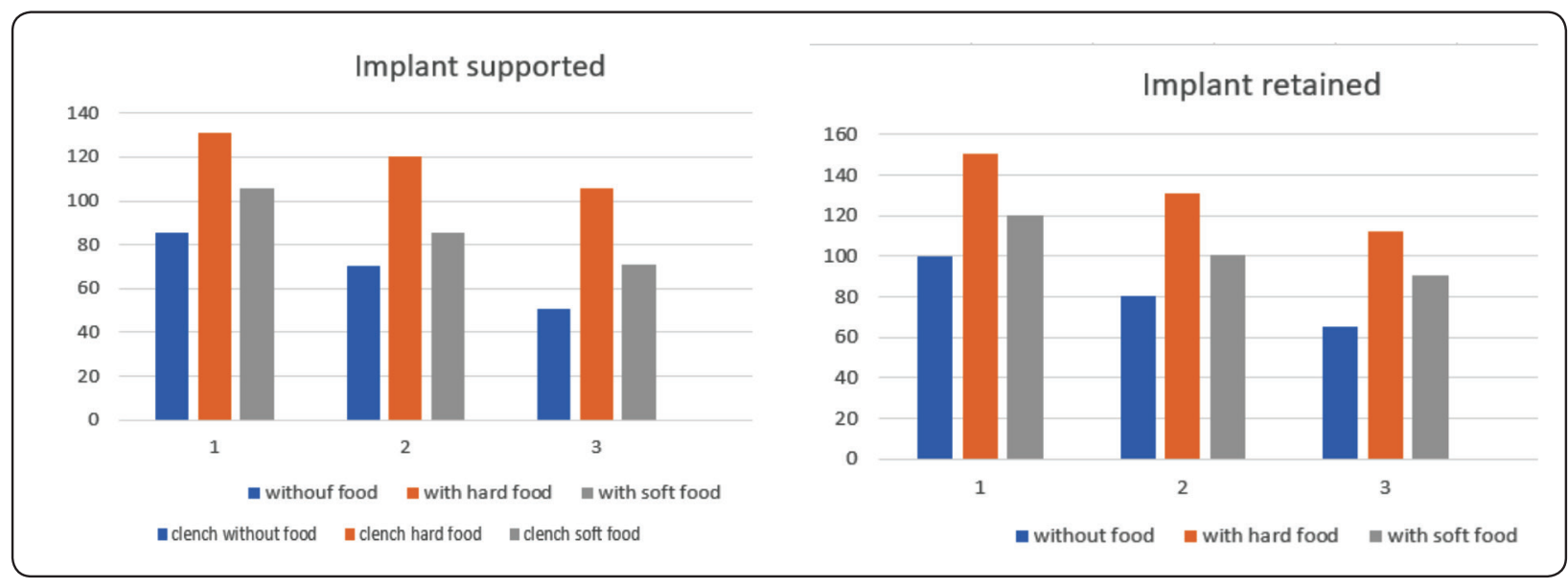

Fig. (3) Comparison of EMG activity of masseter muscle between clenching conditions (without food, with hard food and with soft foods) 
TABLE (2) Comparison of three groups regarding Temporalis muscle activity at different follow up periods and different clenching conditions

\begin{tabular}{|c|c|c|c|c|c|c|c|c|}
\hline & & \multicolumn{2}{|c|}{ At delivery } & \multicolumn{2}{|c|}{ One month } & \multicolumn{2}{|c|}{2 months } & \multirow{2}{*}{$P$ value } \\
\hline & & Mean & SD & Mean & SD & Mean & $\mathrm{SD}$ & \\
\hline \multirow{3}{*}{ Complete denture } & Max. cln & 15.52 & 17.68 & 35.40 & 17.67 & 50.98 & 10.28 & $0.0001 *$ \\
\hline & Hard food & 50.75 & 15.82 & 70.25 & 14.24 & 91.23 & 17.22 & $0.001 *$ \\
\hline & Soft food & 30.12 & 13.58 & 50.10 & 16.63 & 65.10 & 10.32 & $0.001 *$ \\
\hline \multirow{3}{*}{$\begin{array}{l}\text { Implant supported } \\
\text { overdenture }\end{array}$} & Max. cln & 20.35 & 17.59 & 40.02 & 14.87 & 35.51 & 12.22 & $0.001 *$ \\
\hline & Hard food & 72.78 & 12.84 & 80.78 & 11.14 & 90.68 & 10.21 & $0.001 *$ \\
\hline & Soft food & 43.72 & 17.58 & 55.45 & 18.86 & 75.78 & 16.25 & $0.001 *$ \\
\hline \multirow{3}{*}{$\begin{array}{c}\text { Implant retained } \\
\text { overdenture }\end{array}$} & Max. cln & 33.15 & 19.35 & 52.10 & 16.99 & 77.85 & 13.13 & $0.02 *$ \\
\hline & Hard food & 80.25 & $1 . .32$ & 87.20 & 16.47 & 123.58 & 11.34 & $0.02 *$ \\
\hline & Soft food & 60.13 & 18.61 & 77.03 & 12.22 & 95.78 & 11.35 & $0.02 *$ \\
\hline P value & & \multicolumn{2}{|c|}{$0.001 *$} & \multicolumn{2}{|c|}{$0.004 *$} & \multicolumn{2}{|c|}{$0.001 *$} & \\
\hline
\end{tabular}

*p is significant at $5 \%$

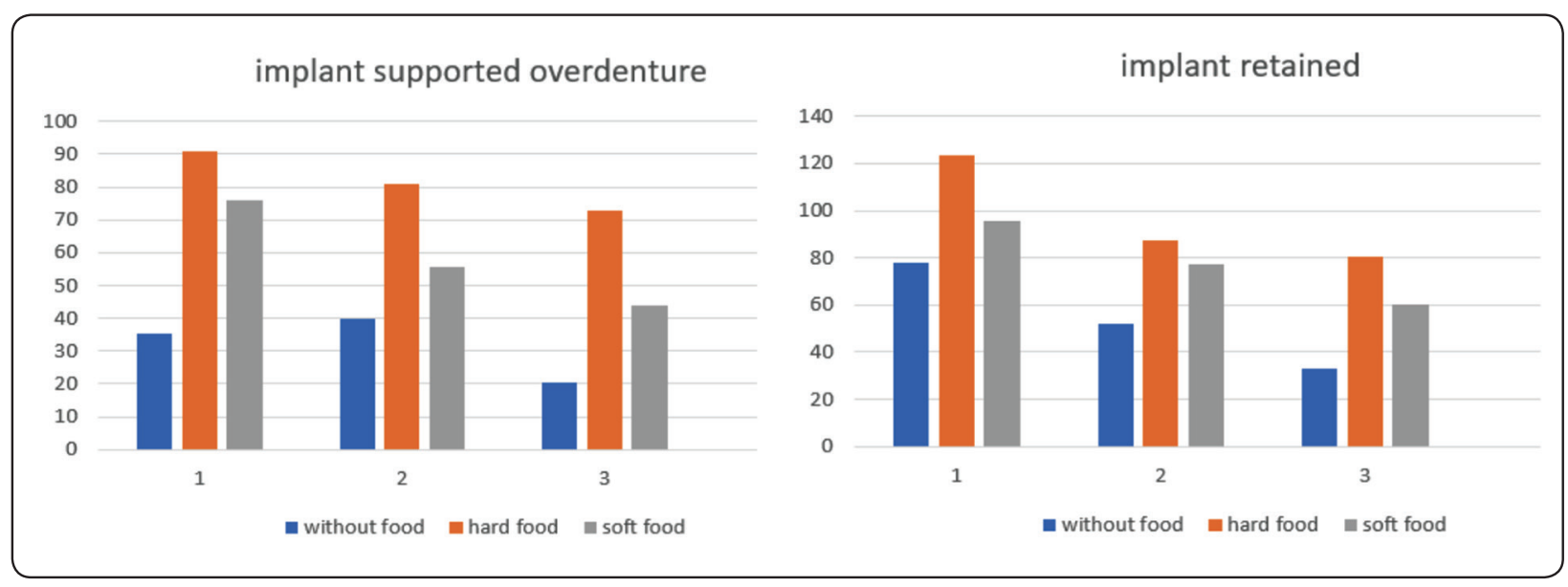

Fig. (4) Comparison of EMG activity of temporalis muscle between clenching conditions (without food, with hard food and with soft foods) 
Comparison of muscle activity between observation times for Masseter and temporalis muscles are presented in table 1 and table 2 respectively. For all groups and clenching conditions, Masseter and temporalis muscle activity increased significantly with passage of time $(\mathrm{p}<.031)$. Multiple comparison revealed a significant difference between each $2 \mathrm{ob}-$ servation times

Comparison of muscle activity between clenching conditions for Masseter and temporalis muscles are presented in fig 3 and fig 4 respectively. For all groups at different observation times, there was a significant difference between clenching conditions. Clenching on hard food showed the highest Masseter and temporalis muscle activity, followed by clenching the soft food and clenching without food showed the lowest muscle activity.

\section{DISCUSSION}

The cross over study design standardized patientbased factors that may affect EMG activity such as age, gender, muscle activity, muscle power, neuromuscular control, and ridge morphology ${ }^{6}$. It also allow the use of reduced patient sample since the same number of patients received different treatments ${ }^{6}$.

The results of this study showed that implant retained overdentures had significant higher Masseter and temporalis muscle activity than conventional denture or implant supported overdentures. This finding is not surprising and in agreement with several previous studies ${ }^{8,11,22,23}$. The increased chewing efficiency with implant retained overdentures compared to conventional dentures agrees with the findings of many authors ${ }^{11,24-26}$ and may be attributed to the improved stability and retention of conventional dentures by osseointegrated implants. It is well known that conventional denture wearers have impaired masticatory function, including lower maximum voluntary bite forces and lower levels of muscular effort during maximum clenching and mastication ${ }^{27,28}$. This could be attributed to denture instability probably prevents denture wearers from using the full potential of their jaw muscles, especially during unilateral biting and chewing ${ }^{29}$.

On the other hand, implant retained overdentures provide increased retention and stability of the mandibular dentures and consequently provide a considerable improvement in muscular activity and mandibular movements, mainly because of their association with a more stabilized occlusion, satisfaction and comfort of patients ${ }^{30}$. Furthermore, implants improved the functional state of the masticatory apparatus. They aided in the establishment of better neuromuscular coordination and enhanced masticatory efficiency by improving the support, stability, and retention of the prosthesis to an extent that is comparable with healthy dentate individuals. It seems that when implants were used, muscle activity, for both anterior temporalis and superficial masseter muscle, was directed towards masticatory function and no effort was required to stabilize or retain the prosthe$\mathrm{sis}^{31}$. Moreover, implant stabilized overdentures, elevate bite force and chewing performance, improve patient satisfaction and decrease discomfort during chewing ${ }^{32,33}$. The increased muscle activity caused by improvement of retention and stability of mandibular dentures is in line with several studies ${ }^{24,34 .}$ 35 and may be attributed to the increased ability to comminute food during mastication ${ }^{36}$. It has been reported that the more stable overdenture enabled reorganization of the neuromuscular system leading to more effective masticatory activity, resulting not only in more effective power-strokes but also in a long-term exercise effect and to more active masticatory muscles ${ }^{37}$ The improvement of muscle activity could be attributed to the activation of periosteal mechanoreceptors through bone deformation which allow most implant patients to discriminate interocclusal thickness and perceive loads, in a phenomenon called 'osseoperception' ${ }^{38-40}$.

The use of healing abutment contact with the denture for support only was reported to decrease soft tissue irritation and preserve alveolar bone. Despite these advantages, it was interesting to 
find that implant supported overdentures without attachments did not provide a significant increase in EMG activity of masseter and temporalis muscle than conventional dentures and still far lower in EMG activity than implant retained overdentures with locator attachments. This may be due to this type of prosthesis still lacks the adequate retention and stability due to absence of attachments and may move during clenching. These movement may irritate the soft tissue and provide discomfort to the patient so he is not be able to exert increased occlusal pressure and increased muscle activity during clenching. Moreover, the healing abutments may act as a fulcrum during maximum clenching which may cause denture base deformation ${ }^{41}$ and mucosal irritation on the distal extensions of the ridge, thus may contribute to the decreased muscle activity. In contrast the locator attachments have internal and external flanges that provide double retention and act as guiding planes ${ }^{13}$ that limit the lateral movements and increased denture stabilization. Thus providing more comfort and satisfaction to the patient ${ }^{5}$ and may be responsible for increased muscle activity. Moreover, the locator have inherent vertical resiliency and not form a fulcrum during clenching thus reduce denture base deformation ${ }^{41}$

For all groups and clenching conditions, Masseter and temporalis muscle activity increased significantly with passage of time. This could be attributed to the increased neuromuscular adaptation to the dentures with time. In fact, neuromuscular control has always been considered as a vital influential factor on the retention and stability of removable restorations. Such finding might be attributed to the improved patient acceptance and adaptation to the prosthesis and better neuromuscular control that the patient naturally acquired by time, irrespective of the type of prosthesis used ${ }^{42}$. A similar observation was reported in another study ${ }^{37}$ in which the authors found a significant improvement of masticatory performance after 3 months of adaptation which characterized by significant increase of maximum muscle contraction, and total muscle work as a re- sult reorganization of the neuromuscular system and increased muscle adaptation accompanied by enhanced contractile capacity of the muscles studied.

The increased muscle activity with hard food compared to soft food is in line with the results of Karkazis ${ }^{30}$. Also, Bakke, et al. ${ }^{11}$ reported higher EMG amplitude with harder food items than soft foods. The authors concluded that the type and texture of the food can significantly influence the muscle activity. The increased EMG with hard foods probably reflects the modulation of the contraction mechanisms through information from intra-oral receptors ${ }^{43,44}$

\section{CONCLUSION}

The limitations of this study included the small patient number and the short follow up period. However, it could be concluded that: Implant retained mandibular overdentures with locator attachments are preferred in terms of improving masseter and temporalis muscle activity compared to implant supported overdenture without attachments or conventional dentures. The stability and the retention (provided by the attachment) are much important than the support of the overdenture prosthesis in improving the muscle activity of patients rehabilitated by implant overdentures.

\section{REFERENCES}

1. Santagata M, Guariniello L, D’Andrea A, Tartaro G. A modified crestal ridge expansion technique for immediate placement of implants: a report of three cases. J Oral Implantol. 2008;34:319-24.

2. Doundoulakis JH, Eckert SE, Lindquist CC, Jeffcoat MK. The implant-supported overdenture as an alternative to the complete mandibular denture. J Am Dent Assoc. 2003; $134: 1455-8$.

3. Rutkunas V, Mizutani H, Takahashi H. Influence of attachment wear on retention of mandibular overdenture. J Oral Rehabil. 2007;34:41-51.

4. ElSyad MA, Denewar BA, Elsaih EA. Clinical and Radiographic Evaluation of Bar, Telescopic, and Locator Attachments for Implant-Stabilized Overdentures in 
Patients with Mandibular Atrophied Ridges: A Randomized Controlled Clinical Trial. Int J Oral Maxillofac Implants. 2018;33:1103-11.

5. Mahanna FF, Elsyad MA, Mourad SI, Abozaed HW. Satisfaction and Oral Health-Related Quality of Life of Different Attachments Used for Implant-Retained Overdentures in Subjects with Resorbed Mandibles: A Crossover Trial. Int J Oral Maxillofac Implants. 2020;35:423-31.

6. ElSyad MA, Ibrahim AE, Nawar NHH, Belal TM. Electromyographic Connectivity of Masseter Muscle with Different Retentive Attachments for Implant Overdentures in Patients with Atrophied Mandibular Ridges: A Crossover Study. Int J Oral Maxillofac Implants. 2019;34:1213-22.

7. Elsyad MA, Khairallah AS. Chewing efficiency and maximum bite force with different attachment systems of implant overdentures: a crossover study. Clin Oral Implants Res. 2017;28:677-82.

8. Elsyad MA, Shawky AF. Masticatory functions with ball and resilient telescopic anchors of mandibular implant overdentures. A cross over study Quintessence Int. 2017;48:615-23.

9. Burns DR, Unger JW, Elswick RK, Jr., Beck DA. Prospective clinical evaluation of mandibular implant overdentures: Part I--Retention, stability, and tissue response. J Prosthet Dent. 1995;73:354-63.

10. Johns RB, Jemt T, Heath MR, Hutton JE, McKenna S, McNamara DC et al. A multicenter study of overdentures supported by Branemark implants. Int J Oral Maxillofac Implants. 1992;7:513-22.

11. Bakke M, Holm B, Gotfredsen K. Masticatory function and patient satisfaction with implant-supported mandibular overdentures: a prospective 5-year study. Int J Prosthodont. 2002;15:575-81.

12. Fueki K, Kimoto K, Ogawa T, Garrett NR. Effect of implant-supported or retained dentures on masticatory performance: a systematic review. J Prosthet Dent. 2007;98:470-7.

13. Elsyad MA, Khairallah AS. Chewing efficiency and maximum bite force with different attachment systems of implant overdentures: a crossover study. Clin Oral Implants Res. 2017;28:677-82.

14. Trakas T, Michalakis K, Kang K, Hirayama H. Attachment systems for implant retained overdentures: a literature review. Implant Dent. 2006;15:24-34.

15. ELsyad MA, Soliman TA, Khalifa AK. Retention and Stability of Rigid Telescopic and Milled Bar Attachments for
Implant-Supported Maxillary Overdentures: An In Vitro Study. Int J Oral Maxillofac Implants. 2018;33:e127-e33.

16. Kleis WK, Kammerer PW, Hartmann S, Al-Nawas B, Wagner W. A comparison of three different attachment systems for mandibular two-implant overdentures: oneyear report. Clin Implant Dent Relat Res. 2010;12:209-18.

17. ELsyad MA, Setta FA, Khirallah AS. Strains around distally inclined implants retaining mandibular overdentures with Locator attachments. An in vitro study. The journal of advanced prosthodontics. 2016;8 116-24.

18. Takanashi Y, Penrod JR, Chehade A, Klemetti E, Savard A, Lund JP et al. Does a prosthodontist spend more time providing mandibular two-implant overdentures than conventional dentures? Int J Prosthodont. 2002;15:397-403.

19. Armijo-Olivo S, Gadotti I, Kornerup M, Lagravere MO, Flores-Mir C. Quality of reporting masticatory muscle electromyography in 2004: a systematic review. J Oral Rehabil. 2007;34:397-405.

20. Feine JS, Lund JP. Measuring chewing ability in randomized controlled trials with edentulous populations wearing implant prostheses. J Oral Rehabil. 2006;33:301-8.

21. Feine JS, Maskawi K, de Grandmont P, Donohue WB, Tanguay R, Lund JP. Within-subject comparisons of implant-supported mandibular prostheses: evaluation of masticatory function. J Dent Res. 1994;73:1646-56.

22. Karkazis H. EMG activity of the masseter muscle in implant supported overdenture wearers during chewing of hard and soft food. J Oral Rehabil. 2002;29:986-91.

23. Van Kampen F, Van Der Bilt A, Cune M, Bosman F. The influence of various attachment types in mandibular implant-retained overdentures on maximum bite force and EMG. J Dent Res. 2002;81:170-3.

24. van Kampen FM, van der Bilt A, Cune MS, FontijnTekamp FA, Bosman F. Masticatory function with implantsupported overdentures. J Dent Res. 2004;83:708-11.

25. van der Bilt A, Speksnijder CM, de Liz Pocztaruk R, Abbink JH. Digital image processing versus visual assessment of chewed two-colour wax in mixing ability tests. J Oral Rehabil. 2012;39:11-7.

26. Toman M, Toksavul S, Saraçog `lu A, Cura C, Hatipog `lu A. Masticatory Performance and Mandibular Movement Patterns of Patients with Natural Dentitions, Complete Dentures, and Implant-Supported Overdentures. . Int J Prosthodont 2012;25:135-7.

27. Slagter AP, Bosman F, Van der Bilt A. Comminution of two artificial test foods by dentate and edentulous subjects. J Oral Rehabil. 1993;20:159-76. 
28. Fontijn-Tekamp FA, Slagter AP, Van Der Bilt A, Van THMA, Witter DJ, Kalk W et al. Biting and chewing in overdentures, full dentures, and natural dentitions. J Dent Res. 2000;79:1519-24.

29. Caloss R, Al-Arab M, Finn RA, Throckmorton GS. The effect of denture stability on bite force and muscular effort. J Oral Rehabil. 2011;38:434-9.

30. Karkazis HC. EMG activity of the masseter muscle in implant supported overdenture wearers during chewing of hard and soft food. J Oral Rehabil. 2002;29:986-91.

31. Chen L, Xie Q, Feng H, Lin Y, Li J. The masticatory efficiency of mandibular implant-supported overdentures as compared with tooth-supported overdentures and complete dentures. The Journal of oral implantology. 2002;28:238-43.

32. Slagter AP, Bosman F, van der Glas HW, van der Bilt A. Human jaw-elevator muscle activity and food comminution in the dentate and edentulous state. Arch Oral Biol. 1993;38:195-205.

33. Diaz-Tay J, Jayasinghe N, Lucas PW, McCallum JC, Jones JT. Association between surface electromyography of human jaw-closing muscle and quantified food breakdown. Arch Oral Biol. 1991;36:893-8.

34. van der Bilt A, van Kampen FM, Cune MS. Masticatory function with mandibular implant-supported overdentures fitted with different attachment types. Eur J Oral Sci. 2006;114:191-6.

35. van Kampen FM, van der Bilt A, Cune MS, Bosman F. The influence of various attachment types in mandibular implant-retained overdentures on maximum bite force and EMG. J Dent Res. 2002;81:170-3.
36. Geertman ME, Slagter AP, van Waas MA, Kalk W. Comminution of food with mandibular implant-retained overdentures. J Dent Res. 1994;73:1858-64.

37. Giannakopoulos NN, Corteville F, Kappel S, Rammelsberg P, Schindler HJ, Eberhard L. Functional adaptation of the masticatory system to implant-supported mandibular overdentures. Clin Oral Implants Res. 2017;28:529-34.

38. Jacobs R, van Steenberghe D. Comparison between implantsupported prostheses and teeth regarding passive threshold level. Int J Oral Maxillofac Implants. 1993;8:549-54.

39. Mericske-Stern R. Oral tactile function in relation to other functions after rehabilitation with implant supported prostheses. In: Osseoperception (ed. R. Jacobs), pp. 169. Catholic University Leuven, Belgium. 1998.

40. Branemark PI. How the concept of osseoperception evolved. In: Osseoperception (ed. R. Jacobs), pp. 43. Catholic University Leuven, Belgium. 1998.

41. ELsyad MA, Fathe Mahanna F, Samir Khirallah A, Ali Habib A. Clinical denture base deformation with different attachments used to stabilize implant overdentures: A crossover study. Clin Oral Implants Res. 2019.

42. Assuncao WG, Barao VA, Delben JA, Gomes EA, Tabata LF. A comparison of patient satisfaction between treatment with conventional complete dentures and overdentures in the elderly: a literature review. Gerodontology. 2010;27:154-62.

43. Horio T, Kawamura Y. Effects of texture of food on chewing patterns in the human subject. J Oral Rehabil. 1989;16:177-83.

44. Plesh O, Bishop B, McCall W. Effect of gum hardness on chewing pattern. Exp Neurol. 1986;92:502-12. 